\title{
PENERAPAN MODEL PEMBELAJARAN THINK PAIR SHARE UNTUK MENINGKATKAN HASIL BELAJAR IPA SISWA
}

\author{
Sudirman \\ SMP N 2 Metro \\ E mail: Sudirman3819@gmail.com
}

\begin{abstract}
Learning science in junior high school raises many problems found on direct instruction, students learn such activity is very low. Students lacking the spirit to learn science, pretend to understand the teacher's explanations. Students in learning activities mediocre both classical learning and teamwork that ultimately student learning outcomes many incompletes. To overcome this, then do action research in order to improve the results of junior high school students learn science through learning model Think Pair Share for Class VIII.1 secondsemester students of SMP Negeri 2 Metro in the academic year 2012/2013. This study time is 3 months. Based on the recapitulation of the data observation learning process and the work of the group, the student learning outcomes can be summarized as follows. In observation of the learning process from the first meeting until the meeting of the 6th, there is increased an activity of students in learning. This happened after learning that teachers undertake improvements at each meeting.
\end{abstract}

Keywords: Learning Activities, Think Pair Share

\section{PENDAHULUAN}

Seiring dengan perkembangan ilmu pengetahuan, maka tidak mungkin bagi para guru untuk mentransfer seluruh fakta dan konsep kepada peserta didik. Wawasan peserta didik harus dikembangkan agar dapat menemukan sendiri fakta dan konsep yang sedang dipelajari, bahkan guru harus berusaha untuk mencari metode yang sesuai dengan situasi dan kondisi, sehingga pembelajaran yang dilaksanakan menjadi efektif. Jika guru tetap mengajarkan seluruh informasi terkait materi, itu artinya guru akan bertindak sebagai sumber informasi tunggal dan yang terpenting karena terdesak waktu untuk mengejar 
pencapaian kurikulum. Hal tersebut mengakibatkan guru akan memilih untuk menyampaikan konsep dan fakta melalui metode caramah. Akibatnya para peserta didik cenderung pasif, tidak bersemangat, dan bosan karena tidak ada aktifitas yang dilakukan, bahkan peserta didik menjadi apatis terhadap mata pelajaran IPA.

IPA termasuk fisika merupakan ilmu pengetahuan yang mempelajari bagian-bagian alam dan interaksi yang ada di dalamnya (Aththibby: 2015). Sebagai salah satu mata pelajaran yang memiliki tujuan membekali siswa untuk mengembangkan penalarannya di samping aspek nilai dan moral bahkan kemampuan nalar dan matematis, maka pembelajaran fisika yang bersifat hafalan menyebabkan pengetahuan dan informasi yang diterima siswa sebatas produk hafalan.

Sifat materi pelajaran IPA tersebut membawa konsekuensi terhadap proses belajar mengajar yang didominasi oleh pendekatan ekspositoris, terutama guru menggunakan metode ceramah.
Sedangkan dalam proses pembelajaran diperlukan totalitas dalam keterlibatan peserta didik, artinya melibatkan pikiran, penglihatan, pendengaran dan psikomotor. Sehingga dalam proses pembelajaran, seorang guru harus mampu mengajak siswa untuk mendengarkan, menggunakan metode yang baik, serta memberi kesempatan untuk menulis dan mengajukan pertanyaan serta tangapan, sehingga terjadi dialog yang menunjukkan proses belajar mengajar yang interaktif.

Menurut Hamalik (2001) belajar adalah proses perubahan tingkah laku individu melalui interaksi dengan lingkungan. Dalam proses belajar mengajar (PBM) akan terjadi interaksi antara peserta didik dan pendidik. Peserta didik atau anak didik adalah salah satu komponen manusiawi yang menempati posisi sentral dalam proses belajar-mengajar (Slameto : 2003).

Perolehan hasil belajar IPA SMP Negeri 2 Metro di Kelas VIII.1 masih jauh dari hasil belajar yang diharapkan. Dari hasil pengamatan langsung yang dilakukan terhadap 
perilaku siswa dalam mengikuti proses belajar mengajar di kelas, masih terlihat siswa yang tidak memperlihatkan penjelasan guru, malas-malasan dalam kegiatan belajar, kurangnya respon siswa terhadap pertanyaan yang diberikan olah guru. Hal ini disebabkan karena siswa merasakan kegiatan pembelajaran yang kurang menarik karena kelas masih didominasi oleh guru sehingga siswa menjadi pasif. Dengan demikian, penulis mencoba melakukan penelitian terhadap aktivitas dan hasil belajar siswa pada siswa Kelas VIII.1 SMP Negeri 2 Metro.

Kurangnya aktivitas belajar IPA siswa dalam kegiatan pembelajaran telah lama menjadi bahan pikiran setiap guru IPA, hal ini terlihat bahwa pada umumnya siswa menampakkan sikap yang kurang antusias, kurang bersemangat dan kurang siap dalam menerima pelajaran. Kurang siapnya peserta didik dalam menerima pelajaran akan mempengaruhi proses pembelajaran, karena akan mengakibatkan suasana kelas kurang aktif dan interaksi timbal balik antara guru dan peserta didik menjadi kurang, serta antara sesama peserta didik tidak terjadi, sehingga peserta didik cenderung pasif dan hanya menerima apa yang diberikan guru dan pada akhirnya hasil belajar mereka rendah dan tidak mencapai standar KKM yang telah ditetapkan.

Berdasarkan hasil hasil observasi pada mata pelajaran IPA Kelas VIII.1 SMP Negeri 2 Metro tahun 2013 ditemukan bahwa hasil belajar siswa pada mata pelajaran tersebut masih rendah. Oleh sebab itu, penggunaan Model Pembelajaran Think Pair Share pada mata pelajaran IPA siswa Kelas VIII.1 semester II SMP Negeri 2 Metro sangat diperlukan dengan harapan dapat meningkatkan hasil belajar peserta didik.

\section{METODE}

Penelitian ini merupakan Penelitian Tindakan Kelas (PTK) dengan pelaksanaan PTK yang meliputi penetapan fokus permasalahan, perencanaan tindakan, pelaksanaan tindakan yang diikuti dengan kegiatan observasi, interpretasi, dan analisis, serta refleksi. Apabila diperlukan, pada 
tahap selanjutnya disusun rencana dilakukan secara berdaur membentuk tindak lanjut. Tahapan tersebut suatu siklus seperti gambar 1 .

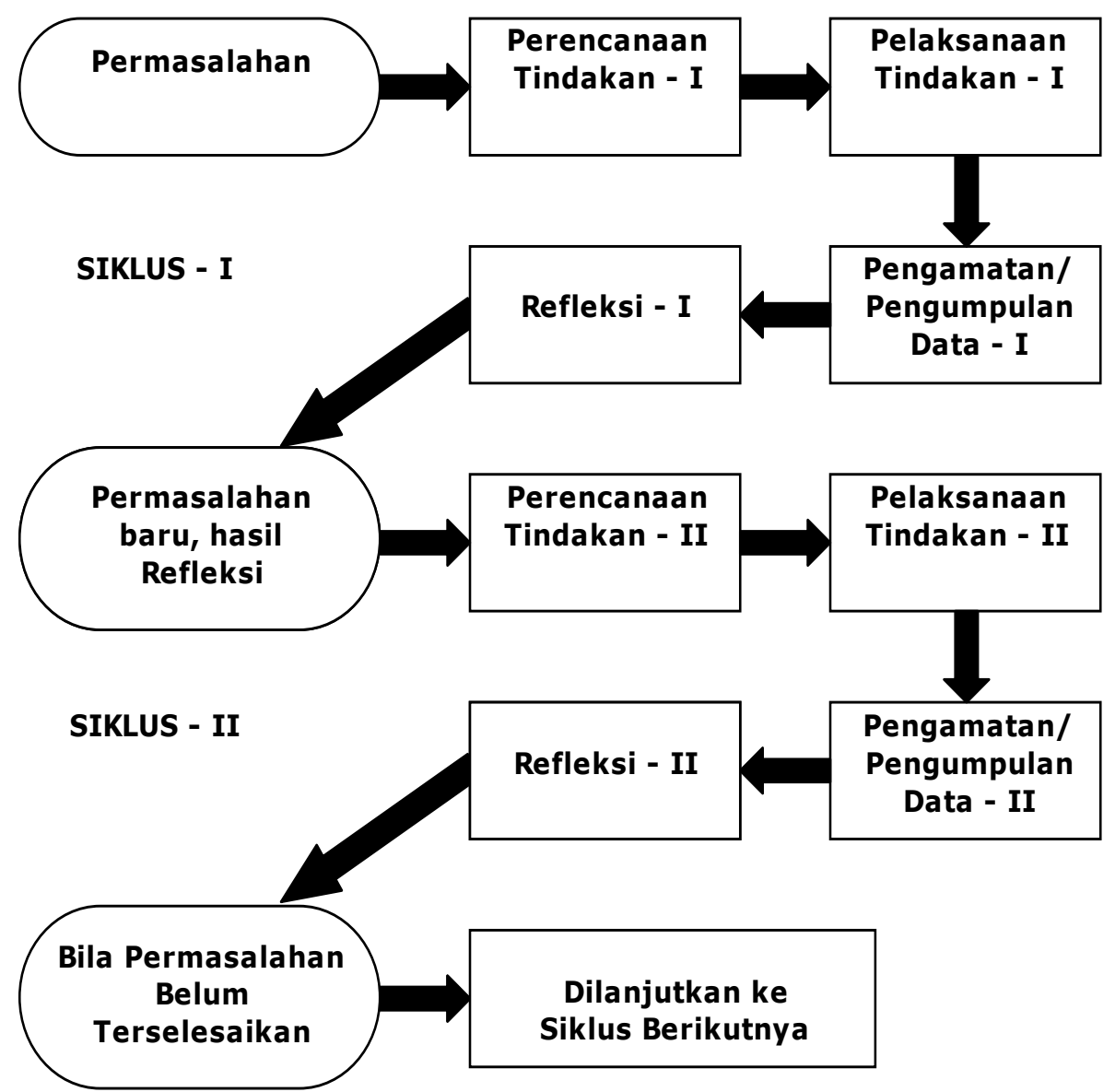

Gambar 1. Siklus Kegiatan PTK (Aidin Adlan, 2011: 19)

Setelah permasalahan ditentukan, berikutnya. Kegiatan pada siklus proses pelaksanaan PTK pada siklus berikutnya dapat berupa kegiatan pertama terdiri atas empat kegiatan. yang sama dengan sebelumnya. Setelah mengetahui keberhasilan atau hambatan dalam tindakan yang Kegiatan yang sama dilakukan jika didapat dari siklus pertama, maka ditujukan untuk mengulangi perlu adanya identifikasi perkeberhasilan, untuk meyakinkan, atau masalahan baru untuk menentukan untuk menguatkan hasil. Umumnya rancangan kegiatan pada siklus kegiatan yang dilakukan pada siklus selanjutnya memiliki berbagai 
tambahan dan perbaikan dari tindakan sebelumnya yang bertujuan untuk mengatasi berbagai hambatan/ kesulitan yang ditemukan dalam siklus sebelumnya.

Subyek penelitian dalam penelitian ini adalah siswa Kelas VIII.1 SMP Negeri 2 Metro tahun 2013 yang berjumlah 35 orang. Untuk mengetahui tingkat ketuntasan hasil belajar siswa, peneliti menggunakan dua kategori ketuntasan belajar yaitu secara perorangan dan secara klasikal. Secara perorangan, siswa dapat dinyatakan tuntas belajar apabila siswa tersebut telah mecapai nilai sesuai kriteria ketuntasan minimal mata pelajaran IPA Kelas VIII.1 SMP
Negeri 2 Metro yang ditetapkan oleh sekolah. Kriteria ketuntasan minimal untuk mata pelajaran IPA Kelas VIII.1 adalah 75. Jadi siswa dapat dinyatakan tuntas belajar apabila telah mencapai skor nilai $\geq 75$.

\section{HASIL DAN PEMBAHASAN}

Data hasil pengamatan dan hasil belajar pada penelitian dari siklus pertama sampai dengan siklus ke-3 , yaitu pengamatan proses belajar, pengamatan kerja kelompok, dan hasil belajar dapat dijelaskan pada tabel rekapitulasi pengamatan proses belajar, kerja kelompok, dan hasil belajar dari siklus 1 s.d. siklus 3 dapat disajikan seperti pada tabel 1

Tabel 1. Rekapitulasi Pengamatan Proses Belajar,

Kerja Kelompok dan Hasil Belajar

\begin{tabular}{|c|c|c|c|c|c|c|c|}
\hline No & Uraian & $\begin{array}{l}\text { S. } 1 \\
\text { P. } 1 \\
\%\end{array}$ & $\begin{array}{l}\text { S. } 1 \\
\text { P. } 2 \\
\%\end{array}$ & $\begin{array}{l}\text { S. } 2 \\
\text { P. } 3 \\
\%\end{array}$ & $\begin{array}{l}\text { S. } 2 \\
\text { P. } 4 \\
\%\end{array}$ & $\begin{array}{l}\text { S. } 3 \\
\text { P. } 5 \\
\%\end{array}$ & $\begin{array}{l}\text { S.3 } \\
\text { P. } 6 \\
\%\end{array}$ \\
\hline \multirow{3}{*}{1} & \multirow{3}{*}{ Proses belajar } & $\mathrm{A}=14,9$ & $A=24,6$ & $\mathrm{~A}=31,4$ & $A=36,6$ & $A=41,2$ & $\mathrm{~A}=45,7$ \\
\hline & & $\mathrm{B}=19,4$ & $\mathrm{~B}=25,7$ & $\mathrm{~B}=29,2$ & $\mathrm{~B}=36,0$ & $\mathrm{~B}=37,7$ & $\mathrm{~B}=45,7$ \\
\hline & & $\mathrm{C}=65,7$ & $\mathrm{C}=49,7$ & $\mathrm{C}=39,4$ & $\mathrm{C}=27,4$ & $\mathrm{C}=21,1$ & $\mathrm{C}=8,6$ \\
\hline \multirow{3}{*}{2} & \multirow{3}{*}{ Hasil kerja kelompok } & $A=0$ & $\mathrm{~A}=10,7$ & $\mathrm{~A}=32,2$ & $\mathrm{~A}=42,9$ & $A=64,3$ & $\mathrm{~A}=71,4$ \\
\hline & & $\mathrm{B}=21,4$ & $\mathrm{~B}=32,2$ & $\mathrm{~B}=25,0$ & $\mathrm{~B}=32,1$ & $\mathrm{~B}=28,6$ & $\mathrm{~B}=28,6$ \\
\hline & & $\mathrm{C}=78,6$ & $\mathrm{C}=57,1$ & $\mathrm{C}=42,8$ & $\mathrm{C}=25,0$ & $\mathrm{C}=7,1$ & $\mathrm{C}=0$ \\
\hline \multirow[b]{2}{*}{3} & \multirow[b]{2}{*}{ Hasil belajar } & $\mathrm{T}=37,1$ & $\mathrm{~T}=45,7$ & $\mathrm{~T}=51,4$ & $\mathrm{~T}=57,1$ & $\mathrm{~T}=71,4$ & $\mathrm{~T}=91,4$ \\
\hline & & $\mathrm{TT}=62,9$ & $\mathrm{TT}=54,3$ & $\mathrm{TT}=48,6$ & $\mathrm{TT}=42,9$ & $\mathrm{TT}=28,6$ & $\mathrm{TT}=8,6$ \\
\hline
\end{tabular}

Keterangan:

$\begin{array}{ll}\mathrm{S} & \text { : siklus } \\ \mathrm{P} & \text { : pertemuan } \\ \mathrm{A} & \text { : amat baik } \\ \mathrm{B} & \text { : baik }\end{array}$

C : cukup

$\mathrm{T}$ : tuntas

B : baik 
Berdasarkan tabel 1. dapat dijelaskan sebagai berikut.

Pengamatan proses belajar pada pertemuan pertama ditemukan aspek kedisiplinan siswa dalam belajar sangat kurang. Siswa banyak yang tidak membuat PR, tidak membawa alat/buku, dan ada yang terlambat datang ke sekolah. Siswa hanya diam mendengarkan penjelasan guru. Pada hasil kerja kelompok ditemukan aspek kebersihan masih perlu mendapat perhatian. Pekerjaan kelompok masih kotor banyak coretan.. Pada pertemuan berikutnya guru memperbaiki pembelajaran terutama pada aspek-aspek tersebut.

Pertemuan ke-2 aspek kepercayaan diri masih kurang, siswa kurang percaya dengan kemampuan sendiri, banyak siswa masih percaya dengan kawannya yang belum tentu betul jawabannya. Aspek ini pada pertemuan ke-3 perlu mendapat perhatian.

Pada hasil kerja kelompok pada ertemuan ke-3, kekurangan terletak pada aspek kerjasama anggota kelompok. Pada pertemuan berikutnya guru lebih memperhatikan kerjasama kelompok yaitun guru menyarankan kepada siswa bahwa dalam kerja kelompok haruslah berdiskusi dalam memecahkan masalah, semua anggota harus aktif dalam pebelajaran kelompok.

Pada pertemuan ke-4 perbaikan yang akan dilakukan pada pertemuan berikutnya adalah aspek keaktifan siswa dalam belajar. Siswa kurang aktif, cendrung duduk diam mendengar penjelasan guru atau penjelasan kawannya. Guru harus memotivasi siswa dalam belajar terutama dalam menanggapi pertanyaan atau jawaban kawannya.

Pada hasil kerja kelompok pada pertemuan ke-4 yang perlu diperbaiki pada pertemuan berikutnya adalah aspek kesesuaian jawaban. Hal ini terlihat masih ada 1 kelompok yang tugas kelompoknya tidak sesuai jawaban dengan perintah tugasnya.

Pada pertemuan ke-5 Pengamatan proses belajar yang perlu diperbaiki adalah aspek pemahaman materi. Pada pertemuan berikutnya guru lebih meningkatkan cara pembelajaran agar pemahaman siswa terhadap materi pelajaran meningkat. 
Aspek kesesuaian jawaban pada hasil kerja kelompok masih perlu mendapat perhatian pada pertemuan ke-6.

Pertemuan ke-6 terlihat bahwa pada proses belajar sudah terdapat peningkatan, hal ini terlihat dari tabel pengamatan proses belajar dari semua aspek pengamatan terdapat peningkatan. Demikian juga pada hasil kerja kelompok pada pertemuan ke-6 dari semua aspek yang dinilai tidak ada yang memperoleh skor $\mathrm{C}=$ Cukup. Ketuntasan belajar juga meningkat yaitu siswa yang tuntas = $91,4 \%$ dan yang tidak tuntas $8,6 \%$. Dengan demikian maka penelitian tindakan kelas terbukti berhasil.

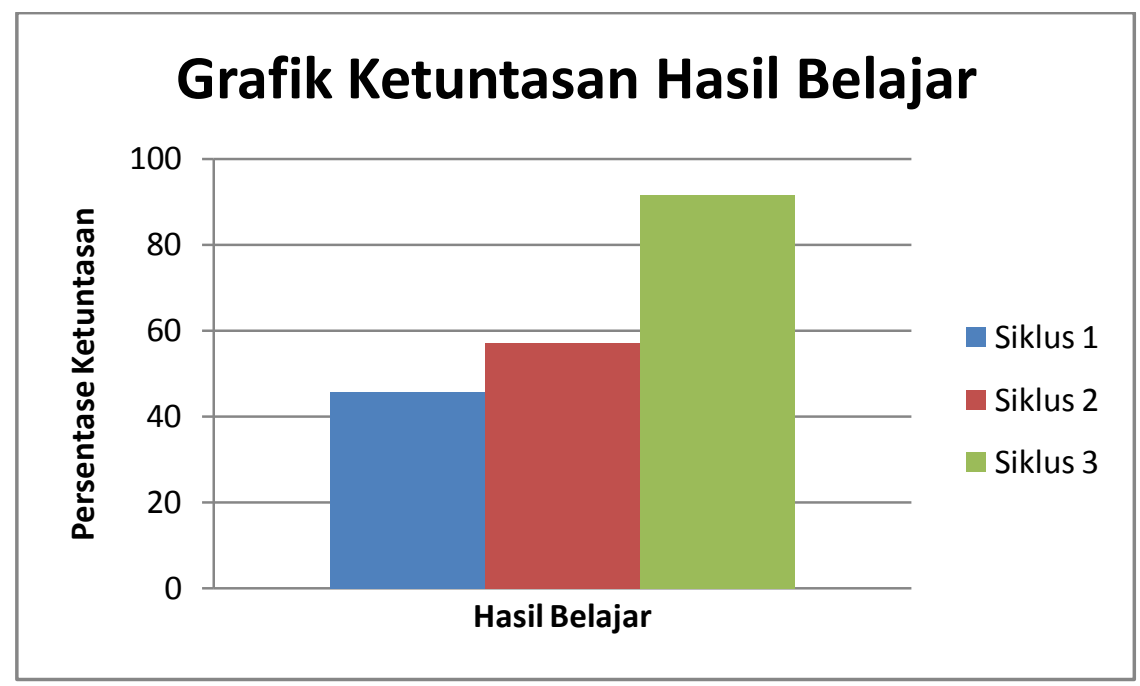

Gambar 2. Grafik Peningkatan Ketuntasan Hasil Belajar

\section{PENUTUP}

\section{Kesimpulan}

Berdasarkan hasil rekapitulasi data pangamatan dan hasil belajar siswa, dapat disimpulkan sebagai berikut.

- Pada pengamatan proses belajar dari pertemuan pertama sampai dengan pertemuan ke-6 terdapat peningkatan aktivitas siswa dalam belajar. Hal ini terjadi setelah ada perbaikan pembelajaran yang dilakukan guru pada setiap pertemuan. Pada pertemuan pertama skor $\mathrm{A}=$ Amat Baik 14,9\%, skor B = Baik 19,4\%, dan skor $\mathrm{C}=$ Cukup $65,7 \%$, sedangkan sampai pada pertemuan ke-6 telah terjadi 
peningkatan menjadi skor $\mathrm{A}=$ Amat Baik 45,7\%, $\mathrm{B}=$ Baik 45,7\%, dan $\mathrm{C}=$ Cukup 8,6\%.

- Pada pengamatan hasil kerja kelompok, pada pertemuan pertama skor $\mathrm{A}=$ Amat Baik 0\%, $\mathrm{B}=$ Baik 21,4\%, dan $\mathrm{C}=$ Cukup 78,6\%. Setelah diadakan perbaikan pembelajaran pada setiap pertemuan telah terjadi peningkatan yaitu pada pertemuan ke-6 skor $\mathrm{A}=$ Amat Baik $71,4 \%, B=$ baik $28,6 \%$ dan $\mathrm{C}=$ Cukup $0 \%$.

- Penilaian hasil belajar terjadi peningkatan penguasaan materi oleh siswa yaitu pada pertemuan pertama siswa yang dinyatakan tuntas $37,1 \%$,tidak tuntas 62,9 $\%$, pada pertemuan ke-6 siswa yang dinyatakan tuntas $91,4 \%$ dan yang tidak tuntas $8,6 \%$

Jadi, secara keseluruhan terdapat peningkatan hasil belajar siswa.

\section{Saran}

- Penelitian ini menggunakan metode dan format penelitian yang sederhana, sehingga perlu diadakan penelitian lebih lanjut untuk mendapatkan hasil penelitian yang lebih akurat.

- Sekolah sebagai lembaga pendidikan formal perlu mengadakan lomba-lomba mata pelajaran IPA untuk memotivasi siswa dalam meningkatkan prestasi.

- Guru hendaknya menggunakan metode dan model pembelajaran yang tepat sesuai karakter materi pelajaran agar mampu meningkatkan hasil belajar siswa.

- Siswa agar belajar dengan disiplin, memiliki minat dan motivasi belajar yang tinggi, aktif dalam belajar, memiliki rasa percaya diri agar dapat memahami materi pelajaran yang disajikan guru.

\section{DAFTAR PUSTAKA}

Aidin Adlan. 2011. Model- Model Pembelajaran. Bandar lampung: LPMP

Aththibby, Arif. 2015. "Pengembangan Media Pembelajaran Fisika Berbasis Animasi Flash opik Bahsan Usaha dan Energi”. Jurnal Pendidikan Fisika (JPF) UM Metro Vol 3 No. 2, Hal. 2533. 
Hamalik, Oemar. 2001. Proses

Belajar Mengajar. Jakarta :

Bumi Aksara.

Slameto. 2003. Belajar dan Faktorfaktor yang Mempengaruhinya. Jakarta: Rineka Cipta. 